\title{
Comparação do custo empregado à concentração proteica de suplementos à base de whey protein em São Luís-Ma
}

\section{Comparison of cost applied to concentration of protein supplements the base of whey protein in São Luís-Ma}

\author{
Raíssa Saraiva Cardoso ${ }^{1}$; Jessica Bianca Passos Pereira²; \\ Marcos Roberto Campos de Macêdo ${ }^{3}$ Rosângela Maria Lopes de Sousa ${ }^{4}$; \\ Alexsandro Ferreira dos Santos 5 .
}

\begin{abstract}
RESUMO: Tem sido crescente a procura por pessoas de todas as idades, pela prática de exercícios físicos e, atrelado a esse crescimento, acontece um aumento do consumo de suplementos alimentares, especialmente os de conteúdo proteicos. Os gastos mensais com suplementos chegam a R \$ 100,00. Neste contexto, o objetivo deste estudo foi comparar o custo monetário com o teor proteico contido em suplementos à base de Whey Protein, comercializados em loja de desporto, na cidade de São Luís - MA. O estudo foi do tipo transversal analítico, realizado em outubro de 2016, em uma loja especializada em produtos de desporto de São Luís - MA. As amostras foram escolhidas conforme disponibilidade na loja. Os dados foram tabulados utilizando o programa Microsoft Excel (2013) e, para a análise, utilizado o mesmo programa. Verificou-se que tanto nos suplementos de origem nacional quanto nos de origem importada, os de caráter concentrado foram os mais acessíveis ( $R$ \$ $15,89)$ e os de caráter isolado os mais dispendiosos ( $\mathrm{R} \$ 28,86)$. Concluiu-se que os Whey Protein que possuem valor mais oneroso são os de caráter isolado e os de valor menos custoso foram os de caráter concentrado, tanto nos suplementos de origem nacional quanto de origem importada.
\end{abstract}

PALAVRAS-CHAVES: Suplementação; Whey protein; Nutrição esportiva; Consumo; Custo.

ABSTRACT: There has been a growing demand by people of all ages, by the practice of physical exercises, and coupled to this growth, there is an increase in the consumption of food supplements, especially those of protein content. The monthly expenses with supplements come to $\mathrm{R} \$ 100.00$. In this context, the objective of this study was to compare the monetary cost with the protein content contained in herbal supplements of Whey Protein, marketed in sports shop in the city of San Luis - MA. The study was a cross-sectional analysis, carried out in October 2016, at a store that specializes in products of sport of São Luís - MA. The samples were chosen according to their availability in the store. The data were tabulated using the Microsoft Excel program (2013) and, for the analysis, used the same program. It was found that, both in supplements of national origin and origin imported, the characters must have been the most affordable (R\$ 15.89) and the characters isolated the more expensive ( $\mathrm{R} \$ 28.86)$. It was concluded that the Whey Protein that have value more costly are the characters alone and those of value less expensive were concentrated character, both in supplements of national origin and origin imported.

KEY WORDS: Supplementation; Whey protein; Sports nutrition; Consumption. Cost.

\footnotetext{
${ }^{1}$ Acadêmica do Curso de Nutrição da Universidade CEUMA. E-mail: raissa_saraiva_cardoso@ @otmail.com

${ }^{2}$ Acadêmica do Curso de Nutrição da Universidade CEUMA. E-mail: jessiepassos@ hotmail.com

${ }^{3}$ Nutricionista, Especialista em Docência do Ensino Superior - Instituto de Ensino Superior Franciscano (IESF). Mestrando em Saúde do Adulto - Universidade Federal do Maranhão. E-mail: marcos.rmacedo@ hotmail.com

${ }^{4}$ Mestre em Saúde Materno-Infantil - Universidade Federal do Maranhão (UFMA); Doutora em Ciências da Saúde - UFMA; Coordenadora do Curso de Nutrição - Universidade CEUMA. E-mail: rmls33 @ hotmail.com

${ }^{5}$ Mestre em Saúde do Adulto e da Criança - Universidade Federal do Maranhão (UFMA); Doutorando em Ciências da Saúde - UFMA; Docente do Curso de Nutrição - Universidade CEUMA. E-mail: fs alexsandro@ yahoo.com.br
} 


\section{INTRODUÇÃO}

Tem sido crescente a procura por indivíduos de todas as idades, pela prática de exercícios físicos, na busca de alcançar um melhor condicionamento físico e forma corporal venerada nas academias (ZANELLA; SCHMIDT, 2012).

Associados ao crescimento pela procura dessa prática, houve o surgimento da conscientização sobre a necessidade de uma alimentação balanceada, que auxilie na busca desse condicionamento, e preservação da saúde (SANTOS et al., 2016).

Segundo Zanella e Schmidt (2012), a agregação de uma nutrição adequada à prática de exercícios físicos agora vem atingindo, além dos que buscavam apenas se encaixar em um padrão de beleza, também aqueles que têm uma preocupação pela manutenção da saúde. Já que, através dessa agregação, além da melhora do desempenho físico, pode haver redução do peso corporal, do percentual de gordura, dos níveis de colesterol, o que consequentemente ajuda na prevenção das doenças crônicas não transmissíveis (PEREIRA; CABRAL, 2007).

Nota-se também que, atrelado a esse crescimento, acontece um aumento do consumo de suplementos alimentares (HIRSCHBRUCH, 2008).

Esses são formulados para auxiliar atletas e praticantes de exercício físico vigoroso no suprimento de suas necessidades adicionais de nutrientes, objetivando rendimento satisfatório nas práticas esportivas. Estes são classificados em: Repositores Hidroeletrolíticos, Repositores Energéticos, Suplementos Proteicos, Suplemento Alimentar para Atletas em Situações Especiais, Compostos Nitrogenados e outras Substâncias, Suplemento de Creatina e Suplemento de Cafeína (AGÊNCIA NACIONAL DE VIGILÂNCIA SANITÁRIA, 2010).

Esses produtos são disseminados pela mídia, como produtos que promovem êxito nos resultados rapidamente, tendo como alvos principais a hipertrofia muscular, redução de gordura corporal, aumento da resistência a exercícios aeróbicos, preconizar a recuperação ou desempenho, perda de peso e alcance rápido ao corpo almejado (SANTOS et al., 2013).

Segundo Hernandez e Nahas (2009), o reparo das microlesões musculares, causadas durante o exercício físico, é conseguido a partir do consumo de proteínas; logo, há uma atenção maior às necessidades proteicas dos atletas.

No entanto, o mito que afirma um grande aumento das necessidades proteicas, em indivíduos interessados no ganho de massa muscular, ainda é bastante expressivo. Este, com 
grande equívoco, pois o consumo de proteína que ultrapassa as necessidades individuais deve ser evitado, visto que as necessidades desse macronutriente em praticantes de exercício físico, quando comparadas às de pessoas sedentárias, é apenas um pouco mais elevada (MAHAN; ESCOTT-STUMP; RAYMOND, 2012).

Goston (2008) constatou em sua pesquisa que $71 \%$ dos participantes menores de 30 anos, que faziam uso de suplementos, tinham intuito de aumentar a massa muscular e que os tipos de suplementos mais consumidos foram os ricos em proteína (38\%). Foi constatado também que $83,4 \%$ dos pesquisados possuíam gastos mensais de até $\mathrm{R} \$ 100,00$ na compra de suplementos nutricionais.

Segundo Sgarbieri (2005), as proteínas oriundas do soro do leite têm ótima composição em aminoácidos, boa digestibilidade e alta biodisponibilidade de aminoácidos essenciais, principalmente os de aminoácidos de cadeia ramificada (BCAA’s).

Esta pesquisa se justifica por notarmos a crescente procura da população pela prática de atividade física e, por consequente, mudanças de hábitos alimentares e utilização de suplementos alimentares, especialmente os de conteúdo proteico oriundos do soro do leite e, levando-se em consideração ainda o valor mensal gasto na compra de suplementos.

$\mathrm{O}$ estudo associou o custo à gramatura de proteína contida em suplementos proteicos vendidos em lojas de desporto. Além disso, notou-se escassez de estudos acerca do tema abordado, em nível nacional, daí então o pioneirismo de tal temática na cidade de São Luís - MA.

Desta forma, o presente trabalho teve como principal objetivo comparar o custo monetário com o teor proteico contido em suplementos alimentares à base do soro de leite, os Whey Protein's, comercializados em loja especializada em produtos para praticantes de atividade física, na cidade de São Luís - MA.

\section{MATERIAL E MÉTODOS}

O estudo foi do tipo transversal analítico. A pesquisa foi realizada em outubro de 2016, em uma loja especializada na comercialização de produtos para praticantes de atividade física da cidade de São Luís - MA.

A escolha da loja para a realização da pesquisa foi por conveniência devido ao grande número de lojas existentes na grande São Luís. Usou-se como critério a localização da mesma, por se situar próximo à Instituição de Ensino Superior dos pesquisadores. 
Foram coletadas 24 amostras e estas foram determinadas de acordo com a disponibilidade dos suplementos na loja, e quando fossem caracterizados como Whey Protein, de diferentes marcas comercializadas no local.

Foram coletadas as informações dos rótulos desses suplementos e o preço empregado a eles.

Após a coleta, os suplementos foram divididos em 3 grandes grupos: o grupo dos Whey Protein's Concentrados, Isolados e Mistos. Dentro destes grupos, foram separados em marcas de origem nacional e importadas.

Os dados foram tabulados em uma planilha de banco de dados do programa Microsoft Office Excel ${ }^{\circledR}$ (2013) e, para a análise dos dados, utilizou-se o mesmo programa. Os dados foram apresentados na forma de média.

Foi feita a divisão do valor monetário empregado ao suplemento, pelo valor proteico informado na embalagem, para assim buscar saber-se o valor pago a cada 100 gramas de proteína ( $\mathrm{R} \$ \mathrm{~g}$ de Proteína). Após a obtenção de todos os resultados, estes foram comparados para chegar-se a uma conclusão sobre qual apresentação de Whey Protein tem o valor mais acessível e qual possui o valor mais oneroso.

O estudo não envolveu seres humanos, logo, não houve necessidade da análise por Comitê de Ética em Pesquisa. Porém, houve a solicitação da autorização dos locais de pesquisa.

Foi mantido o anonimato dos produtos pesquisados e loja, sendo os produtos identificados por seus respectivos grupos.

\section{RESULTADOS}

Foi verificado que, dentre os Whey Protein's de origem nacional, os que possuem o valor mais elevado são os de caráter isolado, apresentando valor médio para cada $100 \mathrm{~g}$ de proteína de $\mathrm{R} \$ 23,57$, enquanto os que possuem valor mais acessível ( $\mathrm{R} \$ 11,12 / 100 \mathrm{~g}$ de Proteína) são os de caráter concentrado, conforme Figura 1: 
Figura 1: Valor de 100g de proteína do soro do leite encontrada em marcas nacionais de Whey Protein comercializados em uma loja especializada.

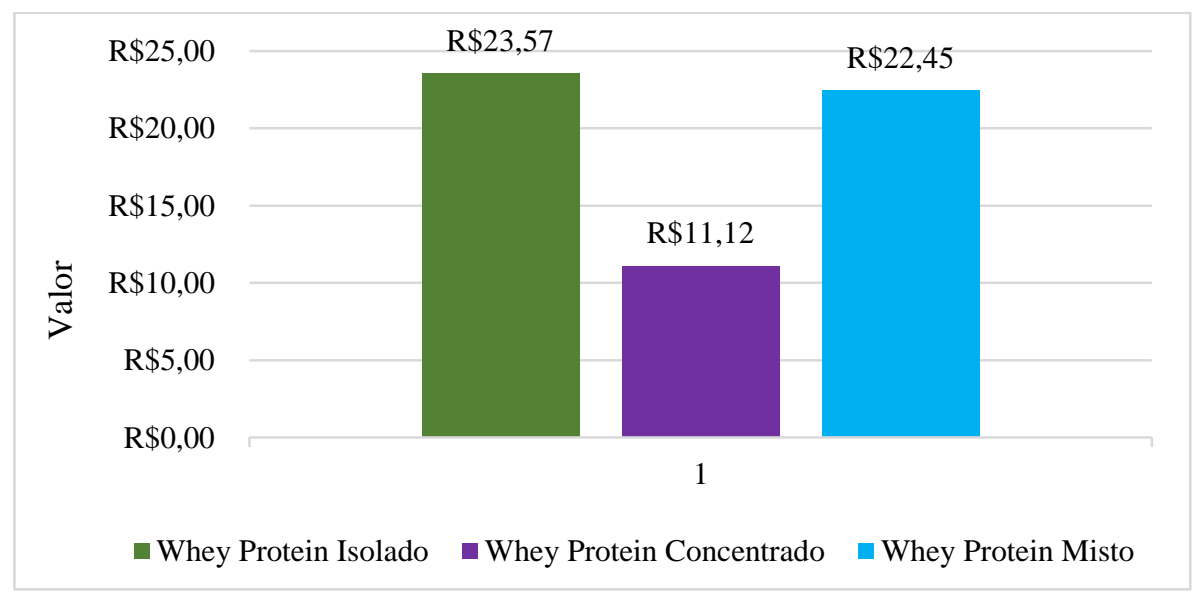

Fonte: Autores

Quando comparadas às marcas de Whey Protein importadas, destaca-se ainda como mais onerosa a apresentação de forma isolada, custando $\mathrm{R} \$ 34,14$, enquanto permanece sendo menos custosa a de apresentação concentrada, que custa $\mathrm{R} \$ 20,65$, conforme Figura 2:

Figura 2: Valor de 100g de proteína do soro do leite encontrada em marcas importadas de Whey Protein comercializados em uma loja especializada.

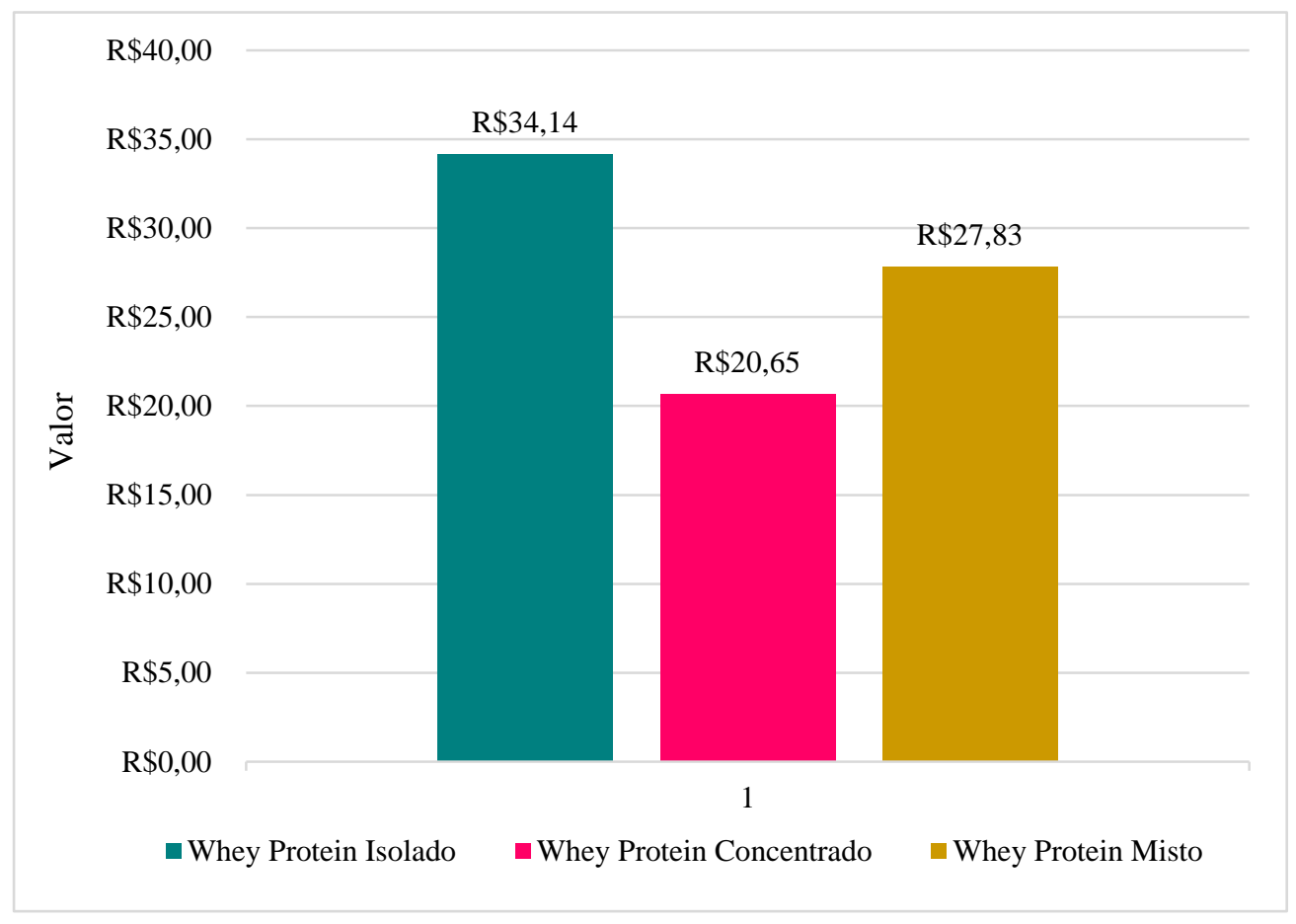

Fonte: Autores. 
Analisando por fim todos os suplementos, sem distinção quanto à origem nacional ou importada, definiu-se que os de característica isolada são os mais dispendiosos, enquanto os menos acessíveis são os de característica concentrada, equivalendo a $\mathrm{R} \$ 28,86$ e $\mathrm{R} \$ 15,89$ cada um, respectivamente (Figura 3):

Figura 3: Valor de 100g de proteína do soro do leite encontrada em diversas marcas de Whey Protein comercializados em uma loja especializada.

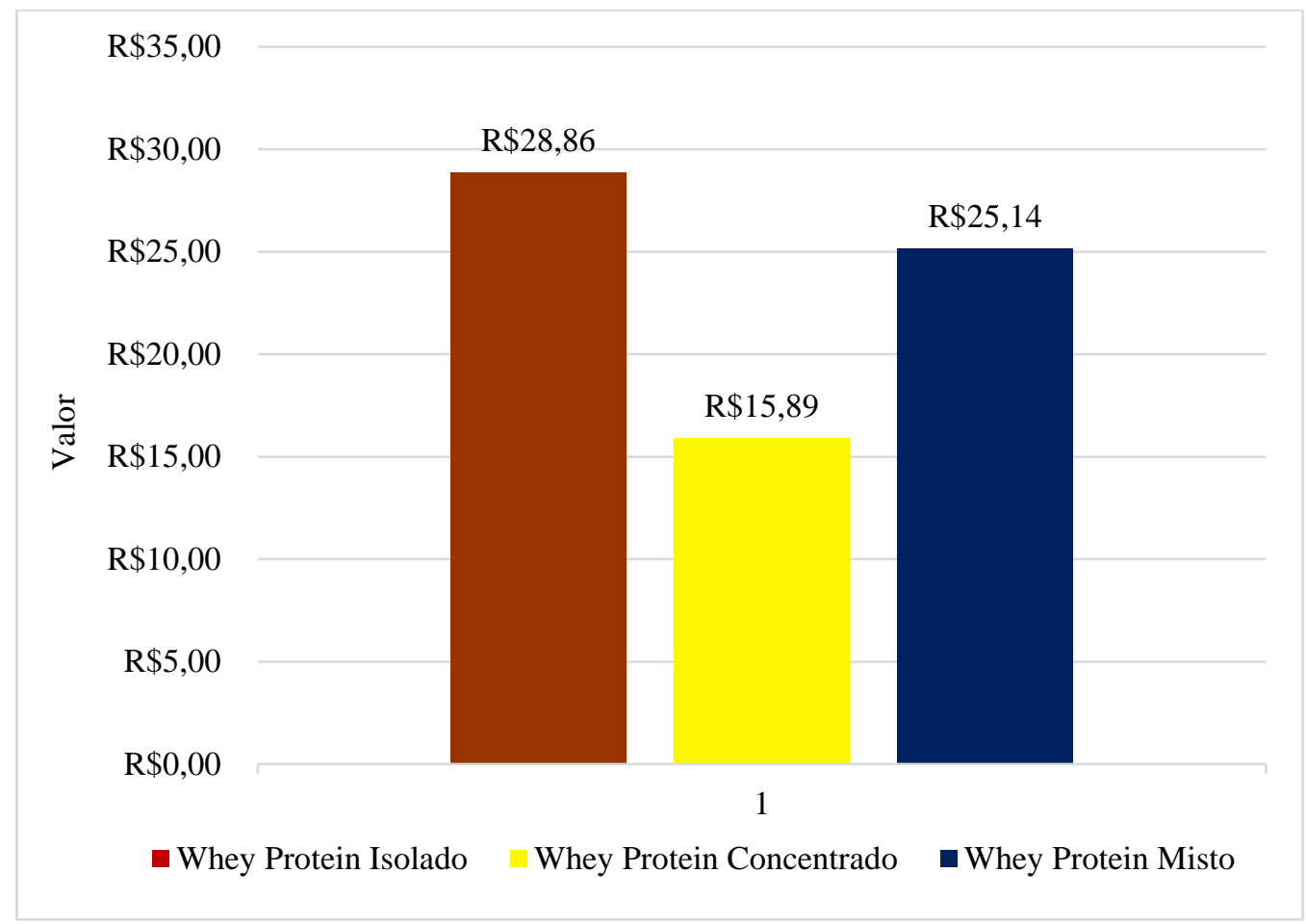

Fonte: Autores.

\section{DISCUSSÃO}

Os resultados parecem apontar que tanto entre as marcas nacionais, quanto entre as marcas importadas, os Whey Protein que possuem o valor mais oneroso para cada $100 \mathrm{~g}$ de Proteína são os de caráter isolado, e os que possuem valor mais acessível são os de caráter concentrado. Quando comparamos os valores de Whey Protein de marcas nacionais e importadas, notamos uma diferença maior nos valores de proteínas isoladas e concentradas, sendo o misto o que possui o valor com menor diferença entre marcas nacionais e importadas.

Por não possuírem pesquisas anteriores que façam o tipo de comparação realizada no presente estudo, sendo este um pioneiro no tema tanto em nível nacional como municipal, não há como fazer relação para encontrar tanto diferenças como semelhanças dos resultados obtidos. 
As limitações para este estudo foram a pouca variedades de marcas nacionais encontradas na loja, tendo entre as importadas uma grande variedade de marcas. Os resultados do estudo seriam mais conclusivos se pudesse ser feita a comparação a estudos anteriores e se houvesse tido a possibilidade de coleta de dados em diferentes lojas, partindo-se do pressuposto de que os valores poderiam mostrar alguma diferença entre os valores.

As conclusões em relação aos resultados têm um alcance limitado devido à pouca variedade de suplementos de marcas nacionais encontradas, atendo-se os valores de 3 marcas nacionais, enquanto as de origem importada possuíam 13 marcas diferentes. Pode-se considerar que o valor da proteína, quando associado ao caráter do Whey Protein (Isolado, Concentrado e Misto), pode variar e ser bem mais custoso em um do que em outro, pelo valor dispendido na produção dos mesmos, quantidade de leite necessária para preparar cada produto, máquinas e utensílios utilizados na produção e qualidade dos resultados físicos obtidos com o consumo de cada um.

\section{CONCLUSÃO}

Em resumo, com os resultados obtidos no presente estudo, podemos concluir que os Whey Protein de caráter isolado, tanto nas marcas nacionais como nas marcas importadas, têm o valor mais custoso por $100 \mathrm{~g}$ de proteína contida no produto e que os de caráter concentrado, de origem nacional e importado, possuem o valor mais razoável a cada $100 \mathrm{~g}$ de proteína presente no produto.

Percebe-se a grande necessidade de mais estudos sobre o custo empregado à concentração proteica de suplementos à base de Whey Protein, visto que os suplementos de origem proteica são os mais consumidos entre os praticantes de atividade física e que, dentro dessa classificação, os à base de Whey Protein são um dos mais utilizados.

\section{REFERENNCIAS}

BRASIL. Resolução RDC ANVISA/MS n. 18, de 27 de abril de 2010. Regulamento Técnico sobre Alimentos para Atletas. Diário Oficial da União, Brasília, DF, 28 de abril de 2010. Seção 1 .

FONTOURA, JS; ECHEVERRIA, LC; LIBERALI, R. Comparação do Consumo de Suplementos Alimentares entre Frequentadores de duas Academia Central e Outra da Periferia de uma Cidade da Região Metropolitana de Porto Alegre/ RS. Revista Brasileira de Nutrição Esportiva, São Paulo, V. 3, N. 15, p. 249 - 263, Mai/Jun., 2009. 
GOSTON, JL. Prevalência do uso de suplementos nutricionais entre praticantes de atividade física em academias de Belo Horizonte: Fatores Associados. Dissertação de Mestrado. Faculdade de Farmácia da UFMG, Belo Horizonte, 2008.

HIRSCHBRUCH, MD; FISBERG, M; MOCHIZUKI, L. Consumo de Suplementos por Jovens Frequentadores de Academias de Ginástica em São Paulo. Revista Brasileira de Medicina do Esporte, São Paulo, V. 14, N. 6, p. 539 - 543, Nov/Dez, 2008.

MAHAN, LK; ESCOTT-STUMP, S; RAYMOND, JL. Krause: Alimentos, Nutrição e Dietoterapia. 13 ed. Rio de Janeiro: Elsevier, 2012. Cap. 24, p. 514.

PEREIRA, JMO; CABRAL, P. Avaliação dos Conhecimentos Básicos sobre Nutrição de Participantes de Musculação em uma Academia na Cidade de Recife. Revista Brasileira de Nutrição Esportiva, São Paulo, V. 1, N. 1, p. 40 - 47, 2007.

PEREIRA, RF; LAJOLO, FM; HIRSCHBRUCH, MD. Consumo de Suplementos por Alunos de Academias de Ginástica em São Paulo. Revista de Nutrição, Campinas - SP. V. 16, N. 3, p. $265-272,2003$.

SANTOS, AN et al. Consumo Alimentar de Praticantes de Musculação em Academias na Cidade de Pesqueira - PE. Revista Brasileira de Nutrição Esportiva, São Paulo, V. 10, N. 55, p. $68-78$, Jan/Fev., 2016.

SANTOS, HVD et al. Consumo de Suplementos Alimentares por Praticantes de Exercício Físico em Academias de Bairros Nobres da Cidade do Recife. Revista Brasileira de Nutrição Esportiva, São Paulo, V. 7, N. 40, p. 204 - 211, Jul/Ago, 2013.

SGARBIERI, VC. Propriedades fisiológicas-funcionais das proteínas do soro de leite. Revista de Nutrição, Campinas - SP. V. 17, N. 4, p. 397-409, 2004.

ZANELLA, A; SCHMIDT, KH. Estado Nutricional e Comportamento Alimentar de Profissionais de Academia de Frederico Westphalen - RS. Revista Brasileira de Nutrição Esportiva, São Paulo, V. 8, N. 35, p. 367 - 375, Set/Out., 2012. 